\title{
Antibacterial effect of Manuka honey on Clostridium difficile
}

\author{
Eric N Hammond ${ }^{1,3^{*}}$ and Eric S Donkor ${ }^{2}$
}

\begin{abstract}
Background: Manuka honey originates from the manuka tree (Leptospermum scoparium) and its antimicrobial effect has been attributed to a property referred to as Unique Manuka Factor that is absent in other types of honey. Antibacterial activity of Manuka honey has been documented for several bacterial pathogens, however there is no information on Clostridium difficile, an important nosocomial pathogen. In this study we investigated susceptibility of $C$. difficile to Manuka honey and whether the activity is bactericidal or bacteriostatic.

Methods: Three $C$. difficile strains were subjected to the broth dilution method to determine minimum inhibitory concentrations (MIC) and minimum bactericidal concentrations (MBC) for Manuka honey. The agar well diffusion method was also used to investigate sensitivity of the $C$. difficile strains to Manuka honey.

Results: The MIC values of the three C. difficile strains were the same $(6.25 \% \mathrm{v} / \mathrm{v})$. Similarly, MBC values of the three C. difficile strains were the same $(6.25 \% \mathrm{v} / \mathrm{v})$. The activity of Manuka honey against all three $\mathrm{C}$. difficile strains was bactericidal. A dose-response relationship was observed between the concentrations of Manuka honey and zones of inhibition formed by the $C$. difficile strains, in which increasing concentrations of Manuka honey resulted in increasing size of zone of inhibition formed. Maximum zone of inhibition was observed at 50\% (v/v) Manuka honey and the growth inhibition persisted over 7 days.
\end{abstract}

Conclusion: C. difficile is appreciably susceptible to Manuka honey and this may offer an effective way of treating infections caused by the organism.

\section{Background}

Clostridium difficile is a Gram positive anaerobic sporeforming bacillus, and is part of the normal gut flora in less than $5 \%$ of humans [1]. The organism is associated with severe infections including diarrhea, pseudomembranous colitis, toxic megacolon, perforation of the colon, and in some cases, sepsis [2]. C. difficile is an important nosocomial agent and currently accounts for $30-50 \%$ of hospital acquired infections with serious economic burden for many countries [3,4]. A number of risk factors for $C$. difficile associated diseases, including the use of certain antibiotics, particularly fluoroquinolones, have been identified [4-6]. In the pathogenesis of diarrhoea caused by the organism, these antibiotics suppress normal flora of the gut and allow the proliferation of $C$. difficile with the production of two toxins (TcdA and TcdB) which cause the disease [6,7].

\footnotetext{
* Correspondence: hammondes@yahoo.com

${ }^{1}$ Global Health Systems Solutions, Accra, Ghana

${ }^{3}$ Department of Microbiology, University of Wales Institute Cardiff, Cardiff, UK Full list of author information is available at the end of the article
}

Antibiotic resistance is a major public health threat especially, with important pathogens such as C. difficile [8]. The problem is associated with overuse and misuse of antibiotics that provide selective pressure favouring the emergence of resistant strains $[9,10]$. The escalating trend of microbial resistance to essential antibiotics, especially multidrug resistance underscores the need for evaluating alternative potential therapeutic agents with antibacterial properties. The use of honey for treating microbial infections dates back to ancient times, though antimicrobial properties of Manuka honey was discovered recently [11-16]. Manuka honey originates from the manuka tree (Leptospermum scoparium) and its antimicrobial effect has been attributed to a property referred to as Unique Manuka Factor that is absent in other types of honey [17]. Lately, studies have shown that the active ingredient in Manuka honey is Methylglyoxal $[18,19]$, and this compound is known to have synergistic effect with some antibiotics such as piperacillin [20]. To date there are numerous studies that have demonstrated the therapeutic

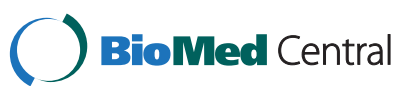


properties of Manuka honey, and have confirmed its activity against a wide range of pathogenic bacteria [21-23]. Consequently, Manuka honey has been recommended for the treatment of ailments such as leg ulcers, pilonidal sinus disease and gastrointestinal infection [24,25]. Though susceptibility of several bacterial pathogens to Manuka honey has been investigated, there is no data on C. difficile, and hence the current study investigated the antibacterial effect of Manuka honey against the organism. In this study, we provide evidence of the susceptibility of C. difficile to Manuka honey and that Manuka honey is bactericidal.

\section{Methods}

\section{C. difficile strains}

Three $C$. difficile strains were used in this study. The three strains were labeled Strains A, B and C. Strain A was the ATCC 9689 strain (PCR-ribotype X). Strains B and $\mathrm{C}$ were clinical isolates of PCR ribotypes 027 and 106 respectively. The strains were provided by the Anaerobe Reference Laboratory at the University of Wales Hospital, and maintained at the Department of Microbiology, University of Wales Institute Cardiff (UWIC). The $C$. difficile strains were grown/stored in Robertson's Cook meat medium (Oxoid, Cambridge, UK) and a purity test [26] was performed on each strain before it was used in the study.

\section{Manuka honey}

Woundcare $^{\mathrm{TM}} 18+$ Active Manuka honey (potency equivalent of greater than $18 \% \mathrm{v} / \mathrm{v}$ phenol) with non-peroxide antibacterial activity from Comvita UK was used in this study.

\section{Determination of MIC/MBC of Manuka honey for C. difficile strains by broth dilution}

Minimum inhibitory concentrations (MIC) refers to the lowest concentration of an antimicrobial that will inhibit the visible growth of a microorganism while minimum bactericidal concentration $(\mathrm{MBC})$ refers to lowest concentration of an antimicrobial that will kill the microorganism [26,27]. MICs of Manuka honey for the $C$. difficile strains were determined using the broth dilution method of susceptibility testing described by European Committee on Antimicrobial Susceptibility Testing [18]. A stock solution of $50 \%(\mathrm{v} / \mathrm{v})$ Manuka honey was prepared by dissolving $12.5 \mathrm{~g}$ honey in $25 \mathrm{ml}$ sterile deionised water. Four millilitres of this solution was pipetted into an empty test tube and labelled 1. Two millilitres of prereduced thioglycolate broth (Oxoid, Cambridge, UK) was pipetted into nine other test tubes. Subsequently $2 \mathrm{ml}$ honey solution from test tube 1 was transferred to test tube 2 containing thioglycolate to prepare a twofold serial dilution. The tubes were inoculated with
$100 \mu \mathrm{l}\left(10^{5} \mathrm{cfu}\right)$ of an overnight culture of a $C$. difficile strain in an anaerobic cabinet (Don Whitley Scientific/ MACS, UK) at $37^{\circ} \mathrm{C}$ for 48 hours. Positive and negative controls were set with $2 \mathrm{mls}$ of the thioglycolate broth (without honey solution) containing $100 \mu \mathrm{l}\left(10^{5} \mathrm{cfu}\right)$ inoculums and $2 \mathrm{ml}$ of the thioglycolate broth without inoculum respectively. After 48 hours incubation, each tube was examined for the presence and absence of turbidity to indicate growth of the microorganism. The first broth or lowest concentration of honey that inhibited growth of the microorganism was designated the MIC $[26,27]$. The results were scored as 'bacterial growth' (+) and 'no bacterial growth' (-). This test was done in triplicate to ensure reproducibility of results.

To determine the $\mathrm{MBC}, 10 \mu \mathrm{l}$ of a sample from the MIC broth that showed no turbidity was streaked onto drug-free medium, prereduced fastidious anaerobic agar plates (Oxoid, Cambridge, UK) in an anaerobic cabinet and incubated at $37^{\circ} \mathrm{C}$ for 24 hours. MBC was defined as the first dilution at which no growth was examined [27]. Any colonies that developed were scored as 'bacterial growth' (+) and 'no bacterial growth' (-).

\section{Evaluation of sensitivity of $C$. difficile strains to Manuka honey by agar diffusion}

Sensitivity of the $C$. difficile strains to Manuka honey was determined using the agar diffusion method of susceptibility testing described by European Committee on Antimicrobial Susceptibility Testing [28]. An overnight culture of the test strain in Robertson's Cook Meat medium (Oxoid, Cambridge, UK) was used to prepare a lawn on a prereduced Fastidious anaerobic agar plate by uniformly swabbing the surface of the agar with a sterile swab stick dipped into the broth culture. Wells were then cut in each agar plate aseptically using a sterile cork borer $(8 \mathrm{~mm}$ in diameter). These wells were subsequently filled with $350 \mu \mathrm{l}$ of $50 \%(\mathrm{v} / \mathrm{v})$ honey solution ( $5 \mathrm{~g}$ honey dissolved in double strength iso-sensitest broth and made up to the $10 \mathrm{ml}$ mark) and incubated at $37^{\circ} \mathrm{C}$ for 7 days in an anaerobic cabinet. The negative control used in this experiment consisted of $350 \mu \mathrm{l}$ double strength iso-sensitest broth (Oxoid, Cambridge, UK) without honey. The zones of inhibition were measured every 24 hours over a period of 7 days using digital vernier callipers (Swiss Precision/ Digimax) and compared to the readings of the control plate. Incubated plates showing zones of inhibition were also monitored from days 1 to 7 for the appearance of C. difficile colonies in the zone of inhibition. For each $C$. difficile strain, the sensitivity experiments were performed for honey solutions of $40 \%, 30 \%, 20 \%$ and $10 \%$ $(\mathrm{v} / \mathrm{v})$ in triplicates. However, the plates were incubated up to 48 hours (2 days), as the inhibition zones of the $50 \% \mathrm{v} / \mathrm{v}$ Manuka honey did not change after 48 hours of incubation. 


\section{Results and discussion}

The MIC and MBC of Manuka honey for the three C. difficile strains investigated is shown in Table 1 . The MIC values of the three $C$. difficile strains were the same $(6.25 \%$ $\mathrm{v} / \mathrm{v})$. Similarly, $\mathrm{MBC}$ values of the three $C$. difficile strains were the same $(6.25 \% \mathrm{v} / \mathrm{v})$. The $\mathrm{MBC} / \mathrm{MIC}$ ratio for each of the strains was 1.0. MIC/MBC are used in confirming susceptibility test results, especially for serious infections, and are also important for monitoring the activity of new antimicrobial agents $[27,29]$. Though there is hardly any data on antibacterial effect of Manuka honey against $C$. difficile, MIC and MBC values of several bacterial agents in relation to Manuka honey have been determined and can be used for comparison with our data. Cooper et al. [30] reported that the MIC of 58 isolates of Staphylococcus aureus from infected wound was $3-4 \%(\mathrm{v} / \mathrm{v})$. In another report, Cooper and Molan [31] determined the MIC of Manuka honey for 20 strains of Pseudomonas aeruginosa isolated from infected wounds to be between $5.5 \%(\mathrm{v} / \mathrm{v})$ and $8.7 \%(\mathrm{v} / \mathrm{v})$. Furthermore, Cooper et al. [32] tested the sensitivity of 17 strains of $P$. aeruginosa isolated from infected burns with Manuka honey (with median level of activity) and observed MICs below 10\% (v/v) for all the test strains. Wilkinson and Cavanagh [33] reported that Manuka honey was effective against many organisms including S. aureus $\left(\mathrm{MIC}_{100}=1.8\right)$, E. coli $\left(\mathrm{MIC}_{100}=3.7\right)$, Salmonella typhimurium $\left(\mathrm{MIC}_{100}=6\right)$ and Proteus mirabilis $\left(\mathrm{MIC}_{100}=7.3\right) \%(\mathrm{v} / \mathrm{v})$. The MIC values observed for the $C$. difficile strains in this study thus appear to be similar to MIC values that have been reported for some other bacteria particularly, $P$. aeruginosa. It is known that bacteriostatic antimicrobial agents have an MBC/MIC ratio greater than or equal to 16 for a given bacterium, while for bactericidal antimicrobial agents the $\mathrm{MBC} / \mathrm{MIC}$ ratio is less than or equal to 4 [34]. The $\mathrm{MBC} / \mathrm{MIC}$ ratios for the different $C$. difficile strains in this study (Table 1 ) suggest that Manuka honey exhibits a bactericidal mode of action against $C$. difficile.

Further evidence of the efficacy of Manuka honey against the $C$. difficile test strains was determined by measuring zone of inhibition in agar well diffusion experiments (Table 2/Figure 1). It was observed that 10 and $20 \%(\mathrm{v} / \mathrm{v})$ Manuka honey concentrations did not show any visible measureable zone of inhibition indicating that at these concentrations, the organisms were not sensitive to the

Table 1 Minimum inhibitory concentrations and minimum bactericidal concentrations of Manuka honey for different C. difficile strains

\begin{tabular}{llccc}
\hline C. difficile strain & PCR ribotype & MIC & MBC & MBC/MIC ratio \\
\hline Strain A (ATCC 9689) & PCR ribotype X & 6.25 & 6.25 & 1 \\
Strain B & PCR ribotype 027 & 6.25 & 6.25 & 1 \\
Strain C & PCR ribotype 106 & 6.25 & 6.25 & 1 \\
\hline
\end{tabular}

Table 2 Sensitivity of $C$. difficile strains to Manuka honey by agar diffusion

\begin{tabular}{ccccc}
\hline Day & $\begin{array}{c}\text { Honey } \\
\text { concentration } \\
(\% \text { v/v) }\end{array}$ & \multicolumn{3}{c}{ Mean zone of inhibition $(\mathrm{mm}) \pm$ SD } \\
\cline { 3 - 5 } & 0 & 0 & 0 & 0 \\
\hline $1-7$ & Strain A (ATCC 9689) & Strain B & Strain C \\
$1-7$ & 10 & 0 & 0 & 0 \\
$1-7$ & 20 & 0 & 0 & 0 \\
1 & 30 & 0 & $9.1 \pm 0.12$ & 0 \\
2 & 30 & $8.4 \pm 0.11$ & $9.3 \pm 0.29$ & 0 \\
1 & 40 & $9.5 \pm 0.31$ & $10.2 \pm 0.33$ & $10.2 \pm 0.27$ \\
2 & 40 & $10.2 \pm 0.4$ & $10.4 \pm 0.20$ & $10.2 \pm 0.24$ \\
1 & 50 & $13.6 \pm 0.78$ & $13.9 \pm 0.32$ & $14.0 \pm 0.24$ \\
2 & 50 & $14.3 \pm 0.50$ & $14.5 \pm 0.22$ & $14.2 \pm 0.23$ \\
3 & 50 & $13.9 \pm 0.50$ & $14.0 \pm 0.28$ & $13.9 \pm 0.26$ \\
4 & 50 & $14.2 \pm 0.63$ & $14.1 \pm 0.42$ & $14.2 \pm 0.28$ \\
7 & 50 & $14.5 \pm 0.52$ & $14.5 \pm 0.41$ & $14.7 \pm 0.45$ \\
\hline
\end{tabular}

\pm SD (standard deviation).

effect of Manuka honey. At 30\% (v/v) Manuka honey concentration, there was no visible effect on Strain C, however zones of inhibition were observed for Strain A (ATCC 9689) and Strain B, with the former being more sensitive. At concentrations of 40 and $50 \%(\mathrm{v} / \mathrm{v})$, all the three $C$. difficile test strains showed considerable sensitivity to Manuka honey and produced comparable zones of inhibition. Generally, in this study, increasing Manuka honey concentrations correlated with increase in the size

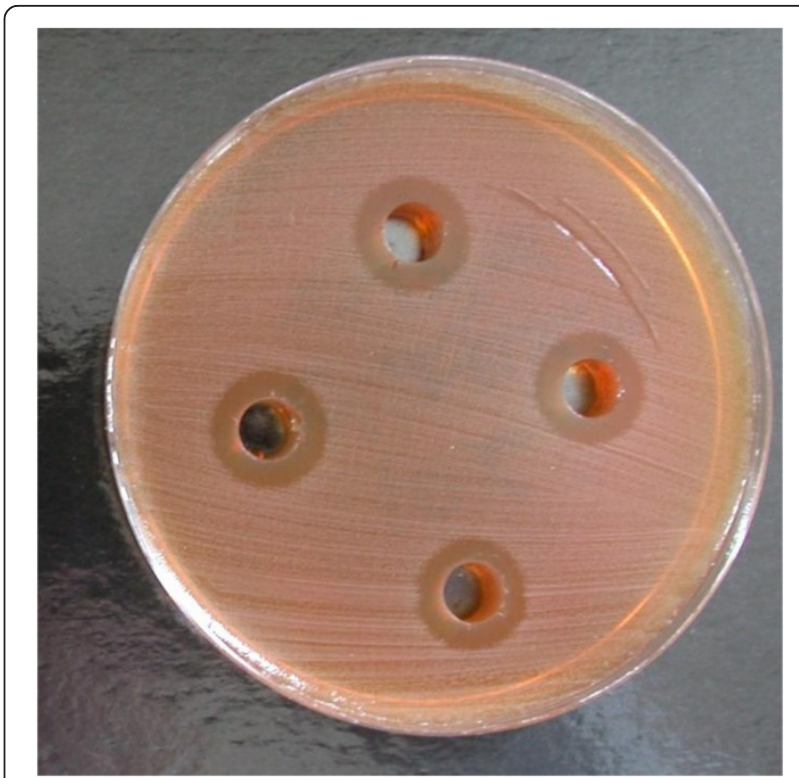

Figure 1 Picture showing inhibition zones after 7 days incubation of Clostridium difficile in the presence of $50 \% \mathrm{v} / \mathrm{v}$ Manuka honey. 
of zone of inhibition and is due to high quantity of antibacterial properties such as Unique Manuka Factor present in Manuka honey as well as its osmolarity which increases with increasing honey concentration [17]. Generally, the test strains were inhibited at lower Manuka honey concentrations in liquid medium (Table 1) than on agar well diffusion plates (Table 2) which may be due to the Manuka honey solution being able to diffuse more uniformly, efficiently and faster in the former.

\section{Conclusion}

In this study, we provide the first data on antibacterial effect of Manuka honey against C. difficile. Our data demonstrates susceptibility of the $C$. difficile strains to Manuka honey with MIC of $6.25 \%(\mathrm{v} / \mathrm{v})$ and MBC of $6.25 \%(\mathrm{v} / \mathrm{v})$. Manuka honey exhibits a bactericidal action against $C$. difficile, a feature which is likely to make Manuka honey highly attractive in the treatment of bacterial infections. Our data adds to the body of research evidence in support of the broad antibacterial spectrum of Manuka honey.

\section{Competing interests}

The authors declare that they have no competing interests.

\section{Authors' contributions}

Laboratory experiments were carried out by ENH. Interpretation of the data was done by ENH and ESD. The manuscript was written by ESD and ENH. Both authors read and approved the final manuscript.

\section{Acknowledgements}

The authors acknowledge the guidance and advice provided by Professor Rose Cooper, Department of Microbiology, School of Health Sciences, University of Wales Institute Cardiff. The technical assistance provided by Mr Leighton Jenkins, also of Department of Microbiology, School of Health Sciences, University of Wales Institute Cardiff, is gratefully acknowledged.

\section{Author details}

${ }^{1}$ Global Health Systems Solutions, Accra, Ghana. ${ }^{2}$ Department of Microbiology, University of Ghana Medical School, Accra, Ghana.

${ }^{3}$ Department of Microbiology, University of Wales Institute Cardiff, Cardiff, UK.

Received: 29 September 2012 Accepted: 25 April 2013

Published: 7 May 2013

\section{References}

1. Larson HE, Price AB, Honour P, Borriello SP: Clostridium Difficile and the aetiology of Pseudomembranous Colitis. Lancet 1978, 311(8073):1063-1066.

2. Sunenshine RH, McDonald LC: Clostridium difficile-associated disease: new challenges from an established pathogen. Cleve Clin J Med 2006, 73(2):187-197.

3. Kelly CP, LaMont JT: Clostridium difficile-more difficult than ever. N Engl J Med 2008, 359(18):1932-1940.

4. Barbut F, Petit JC: Epidemiology of Clostridium difficile-associated infections. Clin Microbiol Infect 2001, 7:405-410.

5. Gorbach SL: Antibiotics and Clostridium difficile. N Engl J Med 1999, 341:1690-1691.

6. Gerding DN, Johnson S, Peterson LR, Mulligan ME, Silva J Jr: Clostridium difficile-associated diarrhea and colitis. Infect Control Hosp Epidemiol 1995, 16:459-477.

7. Borriello SP, Barclay FE, Reed PJ, Welch AR, Brown JD, Burdon DW: Analysis of latex agglutination test for Clostridium difficile toxin $A(D-1)$ and differentiation between $C$. difficile toxins $A$ and $B$ and latex reactive protein. J Clin Pathol 1987, 40:573-580.

8. Huang $H$, Weintraub A, Fang $H$, Nord CE: Antimicrobial resistance in Clostridium difficile. Int J Antimicrob Agents 2009, 34(6):516-522.

9. Alanis AJ: Resistance to antibiotics: are we in the post-antibiotic era? Arch Med Res 2005, 36:697-705.

10. Van de Bogaard AE, Stobberingh EE: Epidemiology of resistance to antibiotics. Links between animals and humans. Int I Antimicrob Agents 2000, 14:327-335.

11. Bogdanov S, Haldimann M, Luginbühl W, Gallmann P: Minerals in honey: environmental, geographical and botanical aspects. J Apic Res 2007, 46(4):269-275.

12. Majno G: The Healing Hand. Man and Wound in the Ancient World. Cambridge, MA: Harvard University Press; 1975:571.

13. Topham J: Why do some cavity wounds treated with honey or sugar paste heal with scarring? I Wound Care 2002, 11:53-55.

14. Cooper R: Using honey to inhibit wound pathogens. Nurs Times 2008, 104(3):46. 48-9.

15. Cooper RA, Jenkins L: The inhibition of biofilms of Pseudomonas aeruginosa with Manuka honey. Ostomy Wound Management 2009, 54(4):70.

16. Kwakman PH, Te Velde AA, de Boer L, Speijer D, Vandenbroucke-Grauls CM, Zaat SA: How honey kills bacteria. FASEB J 2010, 24:2576-2582.

17. Molan PC, Russell KM: Non-peroxide antibacterial activity in some New Zealand honeys. J Apic Res 1988, 27(1):62-67.

18. Atrott J, Haberlau S, Henle T: Studies on the formation of methylglyoxal from dihydroxyacetone in Manuka (Leptospermum scoparium) honey. Carbohydr Res 2012, 361:7-11.

19. Mavric E, Wittmann $S$, Barth $G$, Henle T: Identification and quantification of methylglyoxal as the dominant antibacterial constituent of Manuka (Leptospermum scoparium) honeys from New Zealand. Mol Nutr Food Res 2008, 52(4):483-489.

20. Mukherjee S, Chaki S, Das S, Sen S, Dutta SK, Dastidar SG: Distinct synergistic action of piperacillin and methylglyoxal against Pseudomonas aeruginosa. Indian J Exp Biol 2011, 49:547-551.

21. Taormina PJ, Niemira BA, Beuchat LR: Inhibitory activity of honey against foodborne pathogens as influenced by the presence of hydrogen peroxide and level of antioxidant power. Int J Food Microbiol 2001, 69:217-225

22. Willix DJ, Molan PC, Harfoot CG: A comparison of the sensitivity of wound-infecting species of bacteria to the antibacterial activity of Manuka honey and other honey. J Appl Bacteriol 1992, 73:388-394.

23. Sherlock O, Dolan A, Athman R, Power A, Gethin G, Cowman S, Humphreys $\mathrm{H}$ : Comparison of the antimicrobial activity of Ulmo honey from Chile and Manuka honey against methicillin-resistant Staphylococcus aureus. Escherichia coli and Pseudomonas aeruginosa. BMC Complement Altern Med 2010, 10:47.

24. Thomas M, Hamdan M, Hailes S, Walker M: Manuka honey as an effective treatment for chronic pilonidal sinus wounds. J Wound Care 2011, 20(11):530-533.

25. Lin SM, Molan PC, Cursons RT: The post-antibiotic effect of manuka honey on gastrointestinal pathogens. Int J Antimicrob Agents 2010, 36(5):467-468.

26. Baron JE, Peterson LR, Finegold SM: Bailey and Scott Diagnostic Microbiology. 9th edition. Maryland Heights: C. V. Mosby Co; 1994:175-177. 98-122.

27. European Committee on Antimicrobial Susceptibility Testing: Determination of minimum inhibitory concentration of antibacterial agents by broth dilution: Discussion Document, E. Dis 5.1. Växjö: EUCAST; 2003.

28. European Committee on Antimicrobial Susceptibility Testing: Disk Diffusion Method for Antimicrobial Susceptibility Testing - Version 1.0. Växjö: EUCAST; 2012.

29. Andrews JM: Determination of minimum inhibitory concentrations. J Antimicrob Chemother 2001, 48(Suppl. 1):5-16.

30. Cooper RA, Molan PC, Harding KG: Antibacterial activity of honey against strains of Staphylococcus aureus from infected wounds. JRSM 1999, 92:283-285.

31. Cooper RA, Molan PC: The use of honey as an antiseptic in managing Pseudomonas infection. J Wound Care 1999, 8(4):161-164.

32. Cooper RA, Halas E, Molan PC: The efficacy of honey in inhibiting strains of Pseudomonas aeruginosa from infected burns. J Burn Care Rehabil $2002,23(6): 366-370$ 
33. Wilkinson JM, Cavanagh MA: Antibacterial activity of 13 honeys against Escherichia coli and Pseudomonas aeruginosa. J Med Food 2005, 8(1):100-103.

34. O'Neill A, Chopra I: Preclinical evaluation of novel antibacterial agents by microbiological and molecular techniques. Expert Opin Investig Drugs 2004, 13:1045-1063.

doi:10.1186/1756-0500-6-188

Cite this article as: Hammond and Donkor: Antibacterial effect of Manuka honey on Clostridium difficile. BMC Research Notes 2013 6:188.

\section{Submit your next manuscript to BioMed Central} and take full advantage of:

- Convenient online submission

- Thorough peer review

- No space constraints or color figure charges

- Immediate publication on acceptance

- Inclusion in PubMed, CAS, Scopus and Google Scholar

- Research which is freely available for redistribution 